\title{
QUATERNARY FORCING OF DIVERSITY IN NEOTROPICAL FORESTS
}

COLINVAUX*, P.A., Smithsonian Tropical Research Institute, UNIT 0948, APO AA 34002-0948 U.S.A.

The climate of the Amazon during the last northern glaciation may be taken to represent the normal climate of the basin throughout the Quaternary, since boundary conditions for Amazon and neotropical environments had not otherwise changed since the Andean orogeny and emplacment of the Isthmus of Panama late in the Teritary.

The few radiocarbon dated data describing the climate of the ice age Amazon suggest that the principal climatic forcing was cooling in excess of 6 o $\mathrm{C}$, associated with modest reductions in precipitation. Unlike Africa, the New World tropics were not noticeably arid. The evidence for cooling comes from paleoecological data at the foot of the Equatorial Andes, where temperature sensitive taxa had descended $1500 \mathrm{~m}$ into elevations that now support rain forest. Pollen data from all elevations of the Andes show that climates continued moist throughout glacial cycles, thus making appropriate the application of moist air lapse rates to substantial evidence for cooling in the high Andes also. Evidence that reductions in precipitation were modest in the lowlands come from new pollen records from 2-300 m elevation in the central Amazon of Brazil. A long record of lake sediments from lowland Panama possibly represents a complete glacial cycle. Pollen, phytolith, and other paleoecological data show both cooling and modest reductions in precipitation, in parallel with the Amazon records.

At all stages in glacial cycles, neotropical forests have been subjected to intermediate disturbance tending to prevent competitive exclusion. But the forests have never been fragmented or displaced into "refugia". Vicariance has always been provided by the scales of geography and local disturbance. The forests are dynamic systems of species whose adaptive norms are appropriate to climates of the ice age earth, but which are able to form temporary accomodations in response to climatic change. The modern Amazon rain forest was formed as an ephemeral response to the short-lived warm episode of the Holocene. Local concentrations of species, like those noted on elevated regions surrounding the Amazon basin by refugial theorists, can best be explained because occupying regions of greatest environmental change, with the consequent pattern of invasion and reinvasion necessary with each climatic shift. 